Tropical Journal of Pharmaceutical Research, June 2009; 8 (3): 215-219

(C) Pharmacotherapy Group,

Faculty of Pharmacy, University of Benin

Benin City, 300001 Nigeria.

All rights reserved.

Research Article

Available online at http://www.tjpr.org

\title{
Evaluation of Diuretic Activity of Aqueous and Methanol Extracts of Lepidium sativum Garden Cress (Cruciferae) in Rats
}

\author{
Umang Patel ${ }^{\star}$, Mukul Kulkarni, Vaishali Undale, and Ashok \\ Bhosale \\ Department of Pharmacology, Seth Govind Raghunath Sable College of Pharmacy, Saswad, Pune 412301, India.
}

\begin{abstract}
Purpose: The present study was undertaken to investigate diuretic effect of aqueous and methanol extracts of the dried seeds of Lepidium sativum in normal rats.

Method: Aqueous and methanol extracts of $L$. sativum seeds were administered to experimental rats orally at doses of 50 and $100 \mathrm{mg} / \mathrm{kg}$ p.o. Hydrochlorothiazide $(10 \mathrm{mg} / \mathrm{kg})$ was used as positive control in study. The diuretic effect of the extracts was evaluated by measuring urine volume, sodium and potassium content, conductivity and $\mathrm{pH}$.

Result: Urine volume was significantly increased by the two doses of aqueous and methanol extracts in comparison to control group. While the excretion of sodium was also increased by both extracts, potassium excretion was only increased by the aqueous extract at a dose of $100 \mathrm{mg} / \mathrm{kg}$. There was no significant change in the conductivity and $\mathrm{pH}$ of urine after administration of the L. sativum extracts. The diuretic effect of the extracts was comparable to that of the reference standard (hydrochlorothiazide) and the methanol had the additional advantage of a potassium-conserving effect.

Conclusion: We can conclude that aqueous and methanol extracts of $L$. sativum produced notable diuretic effect which appeared to be comparable to that produced by the reference diuretic HCTZ. The present study provides a quantitative basis for explaining the folkloric use of $L$. sativum as a diuretic agent in Moroccan population.
\end{abstract}

Keywords: Diuretic activity, Lepidium sativum, Herbal medicine, Medicinal plants. 


\section{INTRODUCTION}

Medicinal plants can be important sources of unknown chemical substances with potential therapeutic effects. Besides, the World Health Organization has estimated that over $75 \%$ of the world's population still relies on plant-derived medicines, usually obtained from traditional healers, for basic health-care needs ${ }^{1}$. Lepidium sativum Garden Cress of the family Cruciferae is an annual erect herbaceous plant, growing up to $30 \mathrm{~cm}$. It is a well known culinary herb and the leaves are widely used as a garnish and are consumed raw in salads. The plant is known to possess varied medicinal properties. The seeds are aperient, diuretic, tonic, demulcent, aphrodisiac, carminative, galactagogue and emmenagogue ${ }^{2}$. The seeds are rubefacient and are applied as a poultice for hurts and sprains $^{3}$. The plant also shows teratogenic effect and antiovulatory properties ${ }^{4-7}$. The root is used in the treatment of secondary syphilis and tenesmus ${ }^{3}$. A preliminary pharmacological study of the seeds indicate the presence of cardioactive substance and is shown to have probable action through adrenergic mechanisms ${ }^{8}$. The aqueous extract of $L$. sativum seeds has been reported to exhibit a potent hypoglycaemic activity in normal and streptozotocin induced diabetic rats $^{9}$ as well as an antihypertensive effect when studied in both normotensive and spontaneously hypertensive rats. The effectiveness of this plant in the treatment of bronchial asthma, hiccups, cough with expectoration and bleeding piles has been reported $^{2}$. Preliminary phytochemical study of L. sativum with standard procedures, showed that it contains flavonoids, coumarins, sulphur glycosides, triterpenes, sterols and various imidazole alkaloids ${ }^{10}$. According to previous ethnopharmacological survey carried out in the north central region of Morocco, seeds of $L$. sativum were largely used for the treatment of hypertension and renal disease $^{11}$, but no previous pharmacological or clinical study was carried out to test the diuretic activity of this plant. Since the diuretic effect of $L$. sativum has never been experimentally confirmed, the main aim of the present investigation was to evaluate the claimed diuretic activity of $L$. sativum in rats. Hydrochlorthiazide, was selected as the reference drug, since it is used clinically in some pathologies.

\section{MATERIALS AND METHODS}

\section{Plant material and extraction procedure}

L. sativum seeds were purchased from a local market in Saswad, Pune, India, and authenticated by $\mathrm{Dr}$ AS Upadhyay, a taxonomist at Agharkar Research Institute, Pune. A voucher specimen no. L6721 was deposited in the herbarium of the institute. The aqueous extract was prepared by boiling $1 \mathrm{~g}$ of dried powdered seeds of $L$. sativum in $100 \mathrm{ml}$ of distilled water for $10 \mathrm{~min}$ and left for $15 \mathrm{~min}$ to infuse. Thereafter, the extract was cooled and filtered to remove particulate matter. The filtrate was lyophilized by first freezing at $-22^{\circ} \mathrm{C}$ in a deep freezer for $8 \mathrm{~h}$. The frozen material was then dried in a freeze-dryer at $-40^{\circ} \mathrm{C}$ for $12 \mathrm{~h}$ at $0.01 \mathrm{MPa}$ pressure. The required doses were taken and reconstituted in $10 \mathrm{ml}$ of distilled water just before oral administration. For the methanol extract, the seeds were powdered and defatted with petroleum ether at $60-70^{\circ} \mathrm{C}$. The powdered material was then air-dried and subjected to Sohxlet extraction for $18 \mathrm{~h}$ at $50-55^{\circ} \mathrm{C}$. The extract was thereafter concentrated under vacuum and air-dried. The yield was $10 \%$.

\section{Animals}

Adult male Wistar rats, each in the weight range of $180-200 \mathrm{~g}$, were obtained from the Animal House, SGRS College of Pharmacy, Saswad, Pune, India. The animals were randomly allocated to six treatment groups of 6 animals each and kept in polypropylene cages and housed under standard conditions of temperature, humidity and dark light cycle $(12 h-12 h)$. 


\section{Experimental protocol}

All experimental protocols were approved by the Institutional Animal Ethical Committee of SGRS College of Pharmacy, Saswad, Pune. Diuretic activity was determined following the methods of Kau et $a l^{12}$, with minor modifications. The rats were randomly divided into six groups of six animals each as follows: (1) Control - given $5 \mathrm{ml} / \mathrm{kg}$ body weight of de-ionized water; (2) aqueous extract $-50 \mathrm{mg} / \mathrm{kg}$ body weight; (3) aqueous extract - $100 \mathrm{mg} / \mathrm{kg}$ body weight; (4) methanol extract - $50 \mathrm{mg} / \mathrm{kg}$ body weight; (5) methanol extract $-100 \mathrm{mg} / \mathrm{kg}$ body weight; and (6) hydrochlorothiazide - $10 \mathrm{mg} / \mathrm{kg}$ body weight ${ }^{13-14}$. In all cases, the volume of the dose was administered $5 \mathrm{ml} / \mathrm{kg}$ body weight. The animals were fasted overnight (18 h) prior to the test but with free access to tap water only and then were given an oral loading of normal saline $(0.9 \%)$ of $0.05 \mathrm{ml}$ per $\mathrm{g}$ body weight. Immediately after administration, the rats were paired and placed in metabolism cages. Urine was collected in a graduated cylinder and its volume was recorded at $2 \mathrm{~h}$ intervals for $8 \mathrm{~h}$. Cumulative urine excretion was calculated in relation to body weight and expressed as $\mathrm{ml} / 100 \mathrm{~g}$ b.w. Electrolyte $\left(\mathrm{Na}^{+}\right.$and $\left.\mathrm{K}^{+}\right)$ concentrations, $\mathrm{pH}$ and conductivity were estimated (as described below) from the urine sample of each pair of rats at the end of the experimental period ( $8 \mathrm{~h}$ ) and expressed as mequiv. $/ 100 \mathrm{~g}$ b.w.

\section{Measurement of Urine Output and Analysis of electrolytes}

$\mathrm{Na}^{+}$and $\mathrm{K}^{+}$concentrations were measured using a Toshniwal group model TCM-35 flame photometer. The instrument was calibrated with standard solutions containing different concentrations of $\mathrm{Na}^{+}$and $\mathrm{K}^{+}$. The conductivity was directly determined on fresh urine samples using a conductometer (Toshniwal group model TCM-15). $\mathrm{pH}$ was measured with a pH meter ( Lab India) on fresh urine sample.

\section{Statistical analysis}

The results are expressed as mean values \pm S.E.M. (standard error of mean) of six pairs of rats. Statistical comparison was carried out by analysis of variance (ANOVA). The difference between the means of treated groups and the non-treated control group was evaluated by the Bonferroni Multiple Comparisons Test. The statistical analysis was carried out with software, SigmaPlot ${ }^{\circledR}$, version 2.03. The results were considered statistically significant when was $\mathrm{P}<0.05$.

\section{RESULTS}

The results of the evaluations carried out on the extracts are listed in Tables 1 and 2 . Table 1 shows the urinary volume $(\mathrm{ml} / 100 \mathrm{~g} / 8 \mathrm{~h})$ and other parameters related to excretion such as the conductivity, $\mathrm{pH}$ while Table 2 shows the electrolyte $\left(\mathrm{Na}^{+}\right.$and $\left.\mathrm{K}^{+}\right)$ content (mequiv. $/ 100 \mathrm{~g} / 8 \mathrm{~h}$ ) of the urine of the animals.

\section{Urine volume}

Table 1 shows that the reference diuretic, HCTZ, increased urine volume by $54 \%$. The extracts also caused an increase in urine volume. For the aqueous extract, the increase at doses of $50 \mathrm{mg} / \mathrm{kg}$ body weight and $100 \mathrm{mg} / \mathrm{kg}$ body weight was $29 \%(\mathrm{P}<$ $0.001)$ and $49 \%(P<0.001)$, respectively, compared to the control group while for the methanol extract, is the corresponding values are $18 \%(P<0.01)$ and $41 \%(P<0.001)$, respectively.

\section{Electrolyte excretion}

Table 2 shows the urinary electrolyte content following the administration of the extracts. The dose of $50 \mathrm{mg} / \mathrm{kg}$ aqueous extract produced a significant increase in $\mathrm{Na}^{+}$ excretion, compared with the control group ( $P$ $<0.01)$. The dose of $100 \mathrm{mg} / \mathrm{kg}$ aqueous extract also produced a significant increase in the $\mathrm{Na}^{+}$excretion $(\mathrm{P}<0.001)$. However, only 
Table 1: Effect of oral administration of aqueous and methanol extracts of $L$. sativum and HCTZ on urine volume, diuretic index, conductivity and $\mathrm{pH}$.

\begin{tabular}{llll}
\hline \multicolumn{1}{c}{ Treatment } & \multicolumn{1}{c}{$\begin{array}{c}\text { Dose }(\mathrm{mg} / \mathrm{kg} \\
\text { p.o. }\end{array}$} & $\begin{array}{c}\text { Sodium } \\
(\mathrm{meq} . / 100 \mathrm{~g} / 8 \mathrm{hr}) \times 10^{-2}\end{array}$ & $\begin{array}{c}\text { Potassium } \\
\mathrm{hr}) \times 10^{-2}\end{array}$ \\
\hline Control & - & $54.16 \pm 1.72$ & $17.00 \pm 1.37$ \\
HCTZ & 10 & $91.50 \pm 1.12^{\star \star *}$ & $29.66 \pm 1.75^{\star \star *}$ \\
L. sativum $(\mathrm{Aq})$ & 50 & $62.50 \pm 1.76^{\star *}$ & $16.83 \pm 1.45$ \\
L. sativum $(\mathrm{Aq})$ & 100 & $87.61 \pm 1.25^{\star * *}$ & $25.33 \pm 1.16^{\star *}$ \\
L. sativum (Me OH) & 50 & $60.00 \pm 1.37$ & $17.83 \pm 1.70$ \\
L. sativum $(\mathrm{Me} \mathrm{OH})$ & 100 & $78.66 \pm 1.76^{\star * *}$ & $18.83 \pm 1.07$ \\
\hline
\end{tabular}

${ }^{* *} p<0.01$ and ${ }^{* * *} p<0.001$ compared with the control group (Bonferroni Multiple Comparisons Test). Diuretic index = volume treated group / volume control group.

Table 2: Effect of oral administration of aqueous and methanol extracts of L. Sativum and HCTZ on sodium and potassium excretion in urine.

\begin{tabular}{lllllc}
\hline \multicolumn{1}{c}{ Treatment } & \multicolumn{1}{c}{$\begin{array}{c}\text { Dose } \\
(\mathrm{mg} / \mathrm{kg} \mathrm{b})\end{array}$} & $\begin{array}{c}\text { Urine volume } \\
\mathrm{ml} / 100 \mathrm{gm} / \mathrm{hr})\end{array}$ & $\begin{array}{c}\text { Diuretic } \\
\text { Index }\end{array}$ & Conductivity & $\mathrm{pH}$ \\
\hline Control & ------ & $4.75 \pm 0.13$ & ----- & $12.80 \pm 0.54$ & $7.43 \pm 0.18$ \\
HCTZ & 10 & $7.48 \pm 0.18^{\star \star *}$ & 1.5747 & $14.73 \pm 0.73$ & $7.40 \pm 0.32$ \\
L. sativum $(\mathrm{Aq})$ & 50 & $6.15 \pm 0.18^{\star \star *}$ & 1.2947 & $13.77 \pm 1.36$ & $7.23 \pm 0.24$ \\
L. sativum $(\mathrm{Aq})$ & 100 & $7.12 \pm 0.12^{\star * *}$ & 1.4989 & $14.68 \pm 1.14$ & $7.22 \pm 0.21$ \\
L. sativum $(\mathrm{Me} \mathrm{OH})$ & 50 & $5.61 \pm 0.13^{* *}$ & 1.1810 & $13.89 \pm 0.99$ & $6.88 \pm 0.22$ \\
L.sativum $(\mathrm{Me} \mathrm{OH})$ & 100 & $6.70 \pm 0.134^{* * *}$ & 1.4105 & $14.43 \pm 0.77$ & $6.50 \pm 0.27$ \\
\hline
\end{tabular}

${ }^{* *} p<0.01$ and ${ }^{\star \star *} p<0.001$ compared with the control group. (Bonferroni Multiple Comparisons Test).

the $100 \mathrm{mg} / \mathrm{kg}$ of the methanol extract produced a significant increase in $\mathrm{Na}^{+}$ excretion $(P<0.001)$ when compared to control group. Only HCTZ and the $100 \mathrm{mg} / \mathrm{kg}$ dose of the aqueous extract produced significant increases in potassium excretion. Changes in other parameters - conductivity and $\mathrm{pH}$ - were not significant when compared to control group.

\section{DISCUSSION}

According to previous ethnopharmacological survey carried out in the north central region of Morocco, the seeds of $L$. sativum are largely used for the treatment of hypertension and renal disease ${ }^{11}$, but to the best of our knowledge, no previous pharmacological or clinical study has been carried out to test the diuretic activity of this plant.

Both the aqueous and methanol extract of $L$. sativum showed a dose-dependent increase in urine excretion. With respect to the aqueous extract, the maximum increase in urinary excretion was produced at $100 \mathrm{mg} / \mathrm{kg}$ with a value of $49.89 \%$ compared while the methanol extract $(100 \mathrm{mg} / \mathrm{kg})$ showed an increase of $41.05 \%$ grouping urine volume. The specific conductivity, which is an indirect 
measure of the ionic content of the urine, was increased in a dose-dependent manner in all the extract-treated groups. Thus the diuretic effect of both extracts are indicated by increase in both water excretion and excretion of sodium and potassium. The active principles responsible for the diuretic effects of the extracts of this plant have not yet been elucidated but preliminary phytochemical analysis of the extracts revealed the presence of polar compounds such as flavonoids and steroids. A previous investigation of the composition of $L$. sativum has suggested the presence of flavanoids and steroidal compounds $^{10}$. It may be suggested that these substances might be responsible, at least in part, for the observed diuretic activity and that they may act individually or synergistically. Previous studies have demonstrated also that there are several compounds which could be responsible for the plants diuretic effects such as flavonoids, saponins or organic acids ${ }^{16}$. The effect may be produced by stimulation of regional blood flow or initial vasodilation ${ }^{17}$, or by producing inhibition of tubular reabsorption of water and anions ${ }^{18}$, the result in both cases being diuresis. The increased sodium and water excretion activity also provides strong basis for its proved anti-hypertensive action ${ }^{11}$.

\section{CONCLUSION}

The results obtained in this study provide a quantitative basis to explain the traditional folkloric use of $L$. sativum as a diuretic agent in Moroccan population.

\section{REFERENCES}

1. Farnsworth NR, Akerele O, Bingel AS, Soejarto DD, Guo ZG. Medicinal plants in therapy. Bull.World Health Org. 1985; 63: 83-97.

2. Nadkarni KM. The Indian Materia Medica, $3^{\text {rd }}$ Edn, Dhootapa-peshwar Prakashan Ltd., Panvel, India, 1954, pp 736-737.

3. Chopra RN, Nayar SL, Chopra, LC. Glossary of Indian Medicinal Plants (Including the supplement), Council of Scientific and Industrial Research, New Delhi, India, 1986 pp 845-846.
4. Jamwal KS, Anand KK. Preliminary screening of some reputed abortifacient indigenous plants (Halim). Ind J Pharm, 1966; 24: 218-220.

5. Mulhi BS, Trivedi VO. Vegetable antifertility drugs of India. Q. J. Crude Drug Res. 1972; 12: 19221928.

6. Kamboj VP, Dhawan BN. Research on plants for fertility regulation. Ind. J. Ethnopharmacol. 1982; 6: 191-226.

7. Satyavati GV. Indian plants and products with antifertility effects (A review of literature between 1975-1982). Ancient Sci Life, 1984; 3 (Supp/ 4): 193-202.

8. Vohora SB, Khan MS. Pharmacological studies on Lepidium Sativum, Linn. Ind. J. Physiol. Pharmacol. 1977; 2: 118-120.

9. Eddouks M, Maghrani M, Zeggwagh NA, Michel JB. Study of the hypoglycaemic activity of Lepidium sativum $L$. aqueous extract in normal and diabetic rats. J. Ethnopharmacol. 2005; 97: 391-395.

10. Radwan HM, El-Missiry MM, Al-Said WM, Ismail AS, Abdel Shafeek, Seif-El-Nasr MM. Investigation of the glucosinolates of Lepidium sativum growing in Egypt and their biological activity. Res. J. Medicine Med. Sci. 2007; 2: 127-132.

11. Jouad H, Haloui M, Rhiouani H, El Hilaly J, Eddouks $M$. Ethnobotanical survey of medicinal plants used for the treatment of diabetes, cardiac and renal diseases in the North centre region of Morocco (Fez-Boulemane). J. Ethnopharmacol. 2001; 77: $175-182$.

12. Kau ST, Keddi, JR, Andrews D. A method for screening diuretic agents in the rats. J. Pharmacol. Meth. 1984; 11: 67-75.

13. Abdalaa $S$, Martin-Herreraa $D$, Benjumeaa $D$, Perez-Pazb P. Diuretic activity of Smilax canariensis, an endemic Canary Island species, J. Ethnopharmacol. (article in press), 2008.

14. Abdalaa $S$, Martin-Herreraa $D$, Benjumeaa $D$, Gutierrez-Luisb J. Diuretic activity of some Withania aristata Ait. Fractions. J. Ethnopharmacol. 2008; 117: 496-499.

15. Lu F G-W, Miura K, Yukimura T, Yamamoto K, Effects of extracts from Clerodendron trichotomum on blood pressure and renal function in rats and dogs. J. Ethnopharmacol. 1994; 42: 77-82.

16. Maghrani M, Zeggwagh $N$, Haloui $M$, Eddouks $M$. Acute diuretic effect of aqueous extract of Retama raetam in normal rats. $J$. Ethnopharmacol. 2005; 99: 31-35.

17. Stanic G, Samarzija I. Diuretic Activity of Satureja montana subsp. montana extracts and oil in rats. Phytother. Res. 1993; 7: 363-366.

18. Pantoja CV, Chiang LCH, Norris BC, Concha JB. Diuretic, natriuretic and hypotensive effects produced by Allium sativum (garlic) in anaesthetized dogs. J. Ethnopharmacol, 1993; 31: 325-331. 